\title{
Notice of a fire-ball:
}

\section{Rev. S.E. Dwight}

To cite this article: Rev. S.E. Dwight (1828) Notice of a fire-ball:, Philosophical Magazine Series 2, 3:13, 74-75, DOI: $10.1080 / 14786442808674550$

To link to this article: http://dx.doi.org/10.1080/14786442808674550

$$
\text { 曲 Published online: } 10 \text { Jul } 2009 .
$$

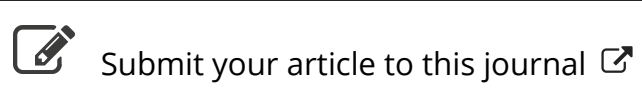

\footnotetext{
Џ Article views: 2
}

Q View related articles $₫$ 


\section{NEW PHENOMENA OF VAPOUR OBSERVED BY CLEMENT \\ DESORMES.}

This philosopher communicated, on the 4 th of December, to the Royal Academy of Sciences, some singular results relative to steam. "When compressed in a boiler, and issuing in a violent and hissing jet, through an orifice made in a pretty large plate, if a flat disk of metal be presented to it, at a little distance from the orifice, the disk is strongly repelled; but if it be brought near and placed against the plate, as if to close the orifice, although the steam issues on all sides like artificial fire-works, and presses against the disk more than before, not only is the disk not driven away, but it adheres to the plate even when the jat is directed downwards. It remains suspended in opposition to its gravity, and can be detached only by force. The same result takes place in an experiment with the wind which issues from the large bellows of a furnace."

\section{NOTICE OF A FIRE-BALL:-BY THE REV. S. E. DWIGHT.}

This meteor appeared on Saturday evening, March 21, 1813, a little before ten o'clock. The sky was extensively overcast, yet the covering was every where thin ; and in the North where the meteor appeared, in various tracts of considerable extent, the stars were in full view. I was standing on a platform on the north side of the house, where I could survey the whole tract of sky over which the meteor passed. When the light first broke upon me, I was looking eastward, and for a moment supposed it to be a flash of very vivid lightning; but from its continuance was led almost instantly to look to the luminary whence it proceeded. The following are the observations which 1 made at the time with regard to it.

1. The meteor, when I first saw it, was about $35^{\circ}$ above the horizon; and from the course of the fence near which 1 stood, I judged its direction, at that time, to be about $\mathrm{N} .20^{\circ} \mathrm{E}$.

2. Its figure was nearly that of an ellipse, with the ends in a slight degree sharpened or angular.

3 . The length of the transverse diameter appeared to be about equal to the apparent diameter of the moon when on the meridian; and that of the conjugate, about three-fourths of the transverse.

4. The colour of the body resembled that of the moon, but was evidently more yellow.

5. A trail of light was formed behind it of considerable length, perhaps of ten or twelve degrees. It was broadest near the body, and decreased in breadth very slowly for about two-fifths of its length ; after which it was an uniform stripe of light, about as wide as the apparent diameter of the planet Venus. The direction of the tail was coincident with that of the transverse diameter.

6 . The ball was much more luminous than the tail, so that the end of the ball connected with the tail was scarcely less distinct in its form than the opposite end.

7. The illumination was so powerful, that all the objects around 
me cast distinct shadows, though less strongly marked than when the moon is at the full.

8. Numerous sparks, of the apparent size of the smaller stars, but much more brilliant, were continually issuing from the ball of the meteor, and after descending a little distance, soon disappeared.

9. The length of time, in which the body was visible, was about eight, or possibly ten seconds.

10. A short time before its disappearance,- say one or two seconds, -three much larger sparks, or luminous fragments, were thrown from the body at the same moment. Two of these were apparently as large as the planet Venus; the third was still larger. These three were the last pieces which I saw leave the body. Their paths were at first nearly parallel with that of the meteor, yet beneath it. From this direction, however, they all deviated constantly and rapidly in parabolic curves, until they seemed falling perpendicularly towards the earth. Each fragment became less and less distinct, until it disappeared. The largest of the three continued visible until it was within about 20 degrees of the horizon.

11. The meteor itself disappeared as suddenly as if, in one indivisible moment, it had passed into a medium absolutely opaque, or as if, at a given moment, it had left the atmosphere; but a few moments afterwards there was a distinct and somewhat extensive illumination over that part of the sky for about a second, as if the light of the departing luminary had been reflected from some unknown surface to the earth.

12. When the meteor disappeared, it was about $30^{\circ}$ above the horizon, and, as 1 judged from the course of the fence, in the direction of N. $45^{\circ} \mathrm{E}$., or $25^{\circ}$ eastward of the place where I first saw it. I concluded that the direction of its path was probably from $W$. by $S$. to $E$. by $N$. It was obviously going from me; its path making an angle with the optic axis of about $60^{\circ}$.

13. Not less than eight minutes, nor more than ten, after the disappearance of the meteor, there was a report very loud and heavy, accompanied with a very sensible jar. Though mistaken for thunder by those who did not see the meteor, it did not much resemble either thunder or the report of a cannon; but was louder, shorter and sharper than either, and was followed by no perceptible echo.

14. A friend of mine, who was in Berlin at the time, about 23 miles due N. of New Haven, saw the meteor distinctly, but made no particular observations concerning it. His estimate of it accorded generally with mine, but it appeared to him larger, more elevated, and somewhat more to the East in its apparent place. - I could not learn that the fragments which fell from it were discovered.-Silliman's Journal, vol. xiii. p. 35 .

ON THE AURORA BOREALIS OF 26TH SEPT.: BY DR. FORSTER.

Boreham, Nov. $95,1827$.

Having seen the remarkable aurora which occurred on the 26 th of September last, slightly mentioned in several of the journals, but no where accurately described, I send you the following brief notes on 